\title{
Links between Information Professionals and Researchers
}

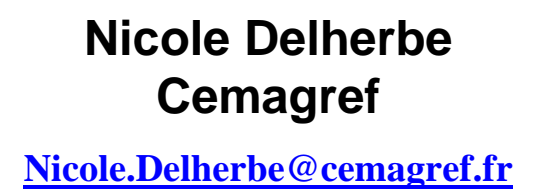

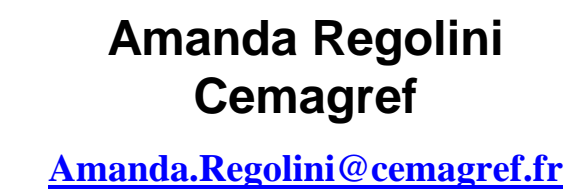

\begin{abstract}
Cemagref is a French public research institute in agricultural and environmental engineering. The first task of the 10 documentation departments of Cemagref is to provide solutions to the our engineers' information needs. The purpose of this communication is to describe various components of our information system, designed: to meet scientists' information needs, to provide a documentary survey, to develop a documentation section consulted through the Intranet network, to highlight the quality of Cemagref's scientific results. The development of these various services results from close and continuous communication between information professionals and researchers.
\end{abstract}

Keywords: Interactive information system, French public research institute, intranet, on line services.

\section{Introduction}

Cemagref, a research institute for agricultural and environmental engineering, is a public establishment with a scientific and technological vocation, setup in France in 1981, under the responsibility of the ministries for agriculture and research. Its 1000-strong personnel conducts applied research in the following areas: understanding and preventing natural risks, management of soils and aquatic environments, engineering of water and waste treatment facilities, engineering of agricultural and agri-foodstuffs facilities.

Cemagref provides solutions to social problems, interfacing with scientific bodies, public authorities and economic groups. It is involved in an expert capacity in the preparation and implementation of public policies.

Its 500 engineers and researchers have varied and complementary scientific and technological skills: from life sciences to engineering sciences, from biology to landscaping, from fluid mechanics to hydrology, ever mindful of

Material published as part of this proceedings, either on-line or in print, is copyrighted by the author with permission granted to the publisher of Informing Science for this printing. Permission to make digital or paper copy of part or all of these works for personal or classroom use is granted without fee provided that the copies are not made or distributed for profit or commercial advantage AND that copies 1) bear this notice in full and 2) give the full citation on the first page. It is permissible to abstract these works so long as credit is given. To copy in all other cases or to republish or to post on a server or to redistribute to lists requires specific permission from the author. the social and economic aspects.

Cemagref is involved in many partnerships with:

- higher education, for the transfer of knowledge;

- other French and European research bodies, with which it coordinates its actions;

- ministries, to which it provides technical support;

- companies and design offices, developing joint research projects and transfer of know-how.

Research activities are conducted in around thirty research units, set up at 10 sites in France.

Cemagref's documentary organization is based on the body's geographical distribution, each site having a documentation center. 22 persons are employed in document handling, with the primary aim of meeting the information needs of the establishment's researchers. The documentary network is coordinated by the IST department (Scientific and Technical Information), at General Management level. Setting up computerized documentation, a thesaurus and a document utilization system has given this network considerable experience in collective work, which is made all the richer by the arrival of Internet. As Cemagref and its research policy develop, the traditional research laboratory libraries are becoming fully-fledged information services at the hub of the various networks. However, the researchers' work remains the main inspiration of all the work conducted. 


\section{N. Delherbe, A. Regolini}

We will look at the contribution of each new technology, taking examples of work carried out at local level, and then present a national initiative intended to disseminate the results of research carried out at Cemagref.

\section{New Information Technologies}

When Internet arrived at Cemagref in 1993, it was no longer a technical novelty. User-friendly interfaces had appeared and information tools were generally well understood, enabling this technology to be rapidly deployed by all the personnel. Information officers quickly took advantage of Internet communication tools. As a result, since 1994 the bibliographical databases of the various sites have been easily accessible to all the establishment's personnel. 1997 was a transitional year at Cemagref. There was extensive renewal of the computer resource, providing all employees with fast, user-friendly access to Internet and the Web in particular.

By setting up documentation resources at each geographical site, Cemagref made close contact between information officer and researcher a major priority based on listening and responding to reciprocal needs. This relationship was in no way weakened by new information and communication technologies. A comparative study carried out in 1997 shows that none of the existing communication resources suffered from the arrival of Internet. All the older forms of information flow are still used today. E-mail, the service used most frequently by all employees, has not replaced the telephone, fax or traditional mail. It has not replaced one-to-one contact either. But Internet resources are used, with varying frequency depending on the individual concerned, as a complement to the other resources.

Documentation services are at a turning point. Traditional library-based documentation has not been replaced by digital, fully virtual documentation. In terms of jobs, information officers' functions have diversified. They must, of course, maintain and develop traditional "hard-copy" documentation. At the same time, they run specific searches and general document monitoring on Internet. They then distribute the results via e-mail and Intranet. That is the local network inside Cemagref. They also play a role in the utilization of the establishment's research via Internet. They are therefore required to train the users of new information technology and this has become an essential role within the establishment's communication system.

Information officers, as the primary users, need to ensure that use of the tool is acquired uniformly and collectively, if optimum use is to be made of the services available. Researchers - the information officers' targeted public must gain confidence through their training in the improved use of services, to derive maximum benefit with a saving in time and frustration. Information officers therefore organize regular training sessions for the use of Internet and Web documentation space in particular. This basic, intermediate and advanced training takes place at the sites themselves, in order to strengthen the direct relations that already exist. It provides users with a selection of introductory guides, a compendium of research engines and a commented and regularly updated bookmark.

The following paragraphs give a more detailed presentation of the type of information disseminated by Internet and work in the area of documentary monitoring.

\section{Dissemination of Scientific and Technical Informa- tion via Intranet}

The Intranet approach is a response to the "horizontal" needs of information officers, enabling the development of on-line services and document dissemination that provide access to all the required information. To avoid unnecessary duplication and to create a common core of information, the information officer network collaborated at national level, with the support of the Cemagref server's webmaster. Since 1997, an IST area, specifically for Scientific and Technical Information, is available via national Web Intranet. These pages, constantly developing as users make their criticisms and suggestions, are designed to make better use of Cemagref's document base and assist its employee's information searches.

A information officer is assigned to each Web page and given the task of organizing the work of a theme-based mini-network and updating the information on the server. This communication support fulfils several objectives.

Firstly, it helps the user to look up a document in the Cemagref catalogs. This heading provides on-line access to Cemagref internal documentary resources, containing more than 130000 bibliographical references. The document bases of the ten sites appear on a single page. The user can run a simultaneous search in as many bases as he/she wishes. On-line help ensures that the search is thorough. An additional service provides a search by title or subject of the base containing the periodicals received by documentation departments. The reader will also find, an on- 


\section{Links between Information Professionals and Researchers}

line index if it exists, and he/she has access to the full text of more than 1500 titles of serials.

Secondly, researchers receive help in making an Internet search via the subject pages. The objective is to provide easy access to the information by guiding the user step-bystep to the relevant sites. Help is provided during the search by a guide that prompts a pre-tested and pre-defined path.

The sites are indicated and an analysis of information on a server is provided, giving details such as waiting times for long connections. The number of links must be restricted to prevent unfruitful routing likely to put the user off the track. Marking of sites is possible, and also the use of paths specially prepared by information professionals, who quickly update addresses when a URL is changed. They also make regular visits to sites, checking for any changes to the contents and informing users of such changes.

Finally, on-line help is available for managing the researcher's personal bibliography. For the purposes of information exchange, personal bibliographies need to be standardized. Their authors must ensure that their bibliography is correctly managed for optimum personal use and for the availability of references found within the various work communities.

Information officers organize "and-hoc" or programmed training sessions in the use

of bibliography management software. The Web heading provides the researchers with a guide to writing bibliographical references and instructions for using the various IT tools available.

The services proposed are created and developed on the basis of careful monitoring of researchers' needs. When a new service is put on line, the opinion of a panel of scientists is sought. This feed-back is used for on-going improvement of the services available.

\section{Results of Documentary Monitoring on Documen- tation Department Intranet}

Documentary monitoring teams are developed in each documentation department. Close contact is maintained with researchers to determine the needs to be met by the monitoring team. There may be frequent meetings and exchanges of opinion during the startup phase to ensure that the best methodology is adopted. Upstream documen- tary monitoring takes the form of searches for scientific documents on formal information services such as databases and validated Web resources. As the monitoring is carried out by information officers who are not necessarily experts in the advanced field of study, the information obtained does not always come from reliable and validated sources. A validation stage is therefore necessary involving experts in the field, i.e. the Cemagref scientists concerned. The data collected and validated in this way are referenced in a specific bibliographical database so that they can be found easily at a later stage. According to Harvard Business School professor, Michael E. Porter, "the philosophy behind monitoring is to give the right information to the right person at the right time to make the right decision". So after searching for the data, then validating and storing it, a selective distribution is made via Intranet. The results of monitoring take the form of two HTML documentary products, freely available on the Cemagref Intranet: a gateway page and a directory page. The gateway page contains all the relevant resources found. They are of several types: free-access databases, organization sites, bibliographies, scientific and technical pages, event advertisements. With the same objectives in mind, the directory page contains the details of international bodies and researchers conducting research into the subject. The primary objective of this page is to enable Cemagref researchers to dialog more easily with fellow researchers. In addition to these data that respond to individual contexts, information officers also provide researchers with the means of continuing the monitoring and updating the database themselves. This is a genuine transfer of know-how from information officer to researcher. The most frequently used means are profiles set up using bibliographical product techniques such as Current Contents (ISI) and e-mail alerts developed by database servers of the Dialog type.

This kind of documentary monitoring, with its many ramifications, is only possible with the support of new technologies.

Having rapidly become major Internet users, information officers have acquired considerable experience in information searches on Internet and the use of Intranet as a communication tool. The boundaries between information, documentation and communication services are becoming blurred and information officers cascade this experience by taking part in regional Web pilot groups. The combination of skills required for these three functions, implemented in a team work context, is seen by Cemagref as an important factor in developing successful Web pages. "Net-information officers" must monitor technological 


\section{N. Delherbe, A. Regolini}

developments (search engines, file formats, information recovery, etc.) to be able to sift the vast amount of data available on Internet, for the information of interest to the researcher. To disseminate this information, they must master communication techniques: ergnomics, graphics, HTML editing, hypertext structuring, etc. Above all they must adapt to the behavior and expectations of experienced or inexperienced "Net-researchers", who are keen to benefit from the added value and whose criticisms and suggestions contribute to a concerted upgrading of the services available. By making this communication tool their own, information officers are furthering the spread of knowledge and adding value to the establishment's work. In addition, they are contributing to the internal communication objective by providing shared tools and easier access to information.

\section{Information Officers Highlight the Quality of Researchers' Work}

Written publications are an excellent way of disseminating the results of research. They are a means to becoming known, publishing results and presenting them for external scrutiny. Pursing this line of thought, we attempted, in late1994, to find references for research work conducted at Cemagref in large international bibliographical data banks. The referencing in the various databases was very limited and haphazard. This situation is explained by the fact that, at present, there is no agreement between the major national and international operators in scientific and technical information aimed at organizing the reference system.

Consequently, organization had to be set up at establishment level to ensure that the publications were referenced and fully utilized.

This measure was launched by a memorandum in November 1994 and then circulated via the various internal communication channels, such as the in-house paper.

This system is not only a structure for information officers. It is closely linked to the day-to-day work of researchers. At each stage in the preparation and development of this initiative, researchers were informed, consulted and listened to. At general management level, the planned operating mode was examined by scientists' representatives. The next stage only began once they had given their approval. The concern to keep authors informed is present at all levels of the establishment. The communication modes are variable and match each particular situation.
The system has three main functions:

- to make the establishment's publications known so that their value, and that of their authors, is recognized;

- to distribute the publications so that the results of research conducted at Cemagref is made known;

- to store all Cemagref documents so that the establishment can capitalize on its work.

We shall see in the following paragraphs, how this system operates and how it adds value to our work before attempting a final assessment.

\section{How the System Adds Value to Cemagref's Work}

Although Cemagref's structure is divided between 10 different geographical sites, it was decided to create one central database and collect the publications at a single storage point. One of the founding principles is to keep both a full bibliographical review and the corresponding hard copy of the full text. Before examining the actual organization of this system, it should be pointed out that any Cemagref employee who has produced a document is concerned and involved. The term "document" refers to a published article, extract of a work, conference address, published conference records, study report, published work, doctoral thesis or student dissertation. At the level of work organization, the Scientific and Technical Information department, part of the General Management, in close contact with the information officers at each site, is responsible for creating the database, known as Cemagrefpublications, and for its utilization.

At the practical level, as soon as a publication is released, its author sends the document and any other relevant information to the information officers of his/her site. These data consist of titles and abstracts, in French and English, bibliographical information and indications concerning the editing of the document prior to publication. This information is frequently send by e-mail. It enables the information officers to prepare the documentary review, i.e. the bibliographical reference of the document. In 1991, before this system was set up, a single documentary review for the whole of Cemagref was prepared collectively by all the information officers, as part of the establishment's document computerization program. A detailed and widelyrecognized methodology is used for this referencing.

For indexing purposes, the information officers also collectively prepared the Cemagref Thesaurus (9000 terms). 


\section{Links between Information Professionals and Researchers}

The document reviews produced are regularly sent in ftp protocol to the IST department. Published documents and paper-format information sheets are sent by mail. The reviews are then loaded in the Cemagref-Publications database using standard software to avoid compatibility problems.

The reviews are systematically reread and checked against the document sent by mail and validated at the documentary and scientific level.

The scientific validation is a guarantee of the quality of the information transmitted. It ensures that data likely to be made known outside the organization are standardized, especially when they concern critical subjects.

At present, Cemagref-Publications contains some 9000 references. It grows on average by 800 references a year. The most common types of documents are conference addresses and study reports, which are generally gray literature and therefore difficult to obtain.

\section{Utilization the Publications}

Having collected the bibliographical references, the next task was, and still is, to make their existence as widely known as possible. We have chosen different ways of doing this, some parallel, some complementary, but never conflicting. The basic principle is that only references of validated documents suitable for distribution (i.e. nonconfidential) are made available on the main bibliographical databases with an input from Cemagref.

The first method was free-access querying of the Cemagref-Publications database on Internet. It was operational from the end of 1995, when Cemagref's Web server (http://wWW.cemagref.fr was opened on Internet. In 1999, nearly 8000 queries were counted. At the technical level, the database, managed using TEXTO document software, is transformed into SQL base and updated twice a month.

The second method is transmission of references to national or international database producers. These partners were selected according to the subjects they handle and/or their involvement in the world of scientific and technical information. Because Cemagref deals with such a large range of subjects, the notion of competition is nonexistent, the only objective for Cemagref being its accurate representation. The technical aspects of data transfer and the volumes exchanged each year are set by agreements. Some producers also wish to supply the documents them- selves. If this is the case, they are sent as photocopies. Depending on the partner concerned, the data transmission format may be quite sophisticated. This meant that initially Cemagref had to develop specific techniques. As the document review used is quite full, it contained all the information required by the formats imposed. The demanding requirement that authors supply titles and abstracts in English proved very useful.

Partnership agreements are currently operational for entries in the following databases: PASCAL (produced by the Institute of Scientific and Technical Information, INISTCNRS), SIGLE (System for Information on Grey Literature in Europe), EAUDOC (database on the subject of water, produced by OIEAU), IALINE (database for agrifoodstuffs). Other partnerships are being studied, especially in the agricultural area. In 1999, roughly 1500 references had been sent.

The third method of utilizing these bibliographical references is in-house use of the data. The reliability of the base is recognized by the establishment's Scientific Management. When research programs or researchers are being assessed, references to documents are extracted from the Cemagref-Publications database. Publication is an important criteria in assessing a researcher. Scientists, widely aware of this procedure, have therefore become more involved in the regular referencing of their writings, giving still greater recognition of the information officers' role in utilizing documents.

We should also add that General Management regularly requests data concerning the number of publications as this provides a validated indicator of activity.

\section{First Report and Development Prospects}

After five years of operation, despite good results, some weaknesses should be pointed out :

Filing a publication for referencing is still at the researcher's discretion. There has been a good deal of information activity, varying in character from site to site, but, despite the general involvement of the personnel, it cannot be said that all the 500 researchers and engineers of Cemagref are efficient authors. At local level, information officers play an essential role, but they must always be "on the look-out" for the latest publication. If the establishment's personnel were to increase, the system would be saturated. 


\section{N. Delherbe, A. Regolini}

This system is sized for the structural organization of the establishment. If there are any changes, we would have to adjust the database structure. This is technically feasible, but would present difficulties for consequent retrospective research. The IT tools used need to be renewed, and integrated with the establishment's main information system.

Changes are also taking place among our databaseproduction partners (subjects, input procedures, organization, etc). We need to adjust rapidly: Cemagref has a tendency to be dependent.

Despite these weaknesses, there are development prospects.

To improve the credibility of this base, a quality initiative was launched as part of a quality policy statement concerning all activities conducted at Cemagref.

The following operational objectives were set:

- to provide exhaustive cover of the publications produced;

- $\quad$ to control processing times;

- to control and guarantee the publicizing system by determining the stages that make it up, their objectives, the norms and rules to be complied with;

- to guarantee traceability of the stages and documents so that causes of non-quality can be detected;

- to control updating of methods and procedures;

- to comply with distribution rules and document confidentiality levels to guarantee information security;

- to organize the process and its tools so that analytical monitoring of the activity can be implemented.

One of the aims of the initiative is to guarantee the system's durability by drafting specific procedures.

Another line of improvement would be to add the full text of the document analyzed to its bibliographical reference. The technical methods need to be developed to include recent technological developments that greatly assist access to the full text, often required by database users. The issue of copyright must also be considered.
At the more general level of gray literature, it would be useful to have easier access to literature produced by French research bodies in particular. This would position Cemagref-Publications in a coordinated global system.

\section{Conclusion}

New technologies have made a considerable contribution in the field of information during the last few years. Cemagref's information professionals, who quickly mastered some of these tools, have played an important role in the rapid development of their profession. Currently, the various information resources are something of a jig-saw puzzle and a constant attempt must be made to produce a system that is consistent within the establishment and with partners' requirements. However, the priority is still to meet the scientists' information needs. This mission is only possible because of the particularly strong day-to-day cooperation of those involved: the researchers and information professionals.

\section{References}

Baligand, M., Cadiou, C., Dao, A., Gardes, Ch./ Regolini, A. (1999). Le Cemagref à l'heure des cyber-documentalistes. Le Micro Bulletin thématique, l'information scientifique et technique et l'outil Internet, expériences, recherches et enjeux pour les professionnels de l'IST, 99 (3), 239-246.

Delherbe, N. (1992). Thésaurus du Cemagref. Antony : Cemagref DICOVA.

Regolini, A. (1997). La Galaxie interactive. L'émergence de pratiques nouvelles liées à l'emploi d'Internet dans un centre de recherche. Le cas de la délégation Rhône-Alpes du Cemagref. Grenoble : Université Stendhal Grenoble 3, UFR Sciences de la communication

\section{Biographies}

Nicole Delherbe is a research engineer of Cemagref., where she works since 1981. She is a part-time teacher at CNAM - INTD in Paris.

Amanda Regolini has twelve years of working experience as an information specialist at Cemagref Grenoble. She is the webmaster of this center since 1998. 